\title{
Relationship of NDVI and oak (Quercus)pollen including a predictive model in the SW Mediterranean region
}

\author{
Rocío González-Naharro \\ Universidad de Extremadura \\ Elia Quirós \\ Universidad de Extremadura \\ Santiago Fernández-Rodríguez \\ Universidad de Extremadura
}

See next page for additional authors

Follow this and additional works at: https://arrow.tudublin.ie/scschcpsart

Part of the Biology Commons, Forest Sciences Commons, Other Physics Commons, and the Other Plant Sciences Commons

\section{Recommended Citation}

González-Naharro R, Quirós E, Fernández-Rodríguez S, Silva-Palacios I, Maya-Manzano JM, Tormo-Molina R, Pecero-Casimiro R, Monroy-Colin A, Gonzalo-Garijo Á. Relationship of NDVI and oak (Quercus) pollen including a predictive model in the SW Mediterranean region. Sci Total Environ. 2019 Aug 1;676:407-419. doi: 10.1016/j.scitotenv.2019.04.213. Epub 2019 May 3. PMID: 31048171.

This Article is brought to you for free and open access by the School of Chemical and Pharmaceutical Sciences at ARROW@TU Dublin. It has been accepted for inclusion in Articles by an authorized administrator of ARROW@TU

Dublin. For more information, please contact arrow.admin@tudublin.ie, aisling.coyne@tudublin.ie, gerard.connolly@tudublin.ie.

Funder: Regional Government, Junta de Extremadura (Spain); European Regional Development Fund; Irish Environmental Protection Agency

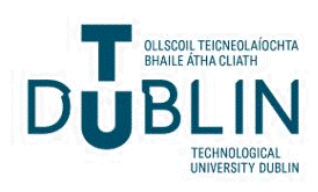




\section{Authors}

Rocío González-Naharro, Elia Quirós, Santiago Fernández-Rodríguez, Inmaculada Silva-Palacios, J. M. Maya-Manzano, Rafael Tormo-Molina, Raúl Pecero-Casimiro, Alejandro Monroy-Colin, and Ángela Gonzalo-Garijo 


\section{Relationship of NDVI and oak (Quercus) pollen including a predictive model in the SW Mediterranean region}

Rocío González-Naharro a , Elia Quirós a , Santiago Fernández-Rodríguez ${ }^{\text {b,* }}$, Inmaculada Silva-Palacios c , José María Maya-Manzano ${ }^{\mathrm{d}}$, Rafael Tormo-Molina ${ }^{\mathrm{e}}$, Raúl Pecero-Casimiro ${ }^{\mathrm{e}}$, Alejandro Monroy-Colin ${ }^{\mathrm{e}}$, Ángela Gonzalo-Garijo ${ }^{\mathrm{f}}$

a Department of Graphic Expression, School of Technology, University of Extremadura, Avda. de la Universidad s/n, Cáceres, Spain

${ }^{b}$ Department of Construction, School of Technology, University of Extremadura, Avda. de la Universidad s/n, Cáceres, Spain

c Department of Applied Physics, Engineering Agricultural School, University of Extremadura, Avda. Adolfo Suárez s/n, Badajoz, Spain

d School of Chemical and Pharmaceutical Sciences, Technological University Dublin, Kevin Street, Dublin, Ireland

e Department of Plant Biology, Ecology and Earth Sciences, Faculty of Science, University of Extremadura, Avda. Elvas s/n, Badajoz, Spain

${ }^{\mathrm{f}}$ Department of Allergology, University Hospital of Badajoz, Avda. Elvas s/n, Badajoz, Spain

\section{H I G H L I G H T S}

- Relationship between NDVI associated to oak trees within three training data polygons

- Analysis of oak (Quercus) pollen concentration measured for a 20 -year period

- 9 years had significant results with Granger causality and 12 years with Spearman test

- Production of oaks tree inventory maps at 15,25 and $50 \mathrm{~km}$-distance

- A predictive model by using Artificial Neural Network was applied $(r=0.77)$.

\section{A R T I C L E I N F O}

\section{Article history:}

Received 4 February 2019

Received in revised form 26 March 2019

Accepted 13 April 2019

Available online 3 May 2019

Editor: SCOTT SHERIDAN

Keywords:

Normalized Difference Vegetation Index (NDVI)

Quercus airborne pollen

Polygon oak trees

\section{G R A P H I C A L A B S T R A C T}

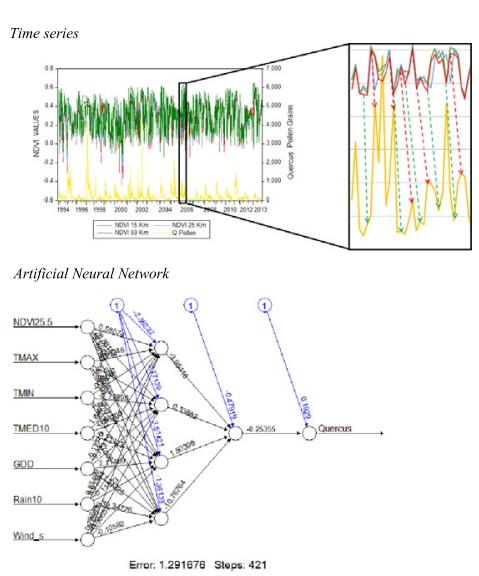

\section{A B S T R A C T}

Techniques of remote sensing are being used to develop phenological studies. Our goal is to study the correlation among the Normalized Difference Vegetation Index (NDVI) related with oak trees included in three set data polygons (15, 25 and $50 \mathrm{~km}$ to aerobiological sampling point as NDVI-15, 25 and 50), and oak (Quercus) daily average pollen counts from 1994 to 2013. The study was developed in the SW Mediterranean region with continuous pollen recording within the mean pollen season of each studied year. These pollen concentrations were compared with NDVI values in the locations containing the vegetation under a study based on two cartographic sources: the Extremadura Forest Map (MFEx) of Spain and the Fifth National Forest Inventory (IFN5) from Portugal. The importance of this work is to propose the relationship among data related in space and time by Spearman and Granger causality tests. 9 out of 20 studied years have shown significant results with the Granger causality test between NDVI and pollen concentration, and in 12 years, significant values were obtained by Spearman test. The distances of influence on the contribution of Quercus pollen to the sampler showed statistically significant results depending on the year. Moreover, a predictive model by using Artificial Neural Network (ANN) was

\footnotetext{
* Corresponding author.

E-mail address: santiferro@unex.es (S. Fernández-Rodríguez).
} 
Granger causality test

Akaike information criterion (AIC)

Artificial Neural Network (ANN) applied with better results in NDVI25 than for NDVI15 or NDVI50. The addition of NDVI25 with the lag of 5 days and some weather parameters in the model was applied with a RMSE of 4.26 (Spearman coefficient $r=0.77$ ) between observed and predicted values. Based on these results, NDVI seems to be a useful parameter to predict airborne pollen.

(c) 2019 Elsevier B.V. All rights reserved.

\section{Introduction}

Techniques of remote sensing (such as MODerate resolution Imaging Spectroradiometer (MODIS) and Advanced Very High Resolution Radiometer (AVHRR), among others) are being used to develop phenological studies (Liu et al., 2017; Walker et al., 2015; Zhang, 2015). The satellite sensors capture the annual variability and the phenological dynamics of vegetation by land surface phenology (LSP) (de Beurs and Henebry, 2004). The phenology of the vegetation and the pollen grain emissions to the air have been widely studied, showing a close relationship (Romero-Morte et al., 2018; Tormo-Molina et al., 2015; VelascoJiménez et al., 2015). Satellite-derived sources, such as the Normalized Difference Vegetation Index (NDVI), have been used to capture the phenology of different types of vegetation (oak and grass) in the Mediterranean environment (Liu et al., 2017). The NDVI is measured as follows: $\mathrm{NDVI}=(\mathrm{Ch} 2-\mathrm{Ch} 1) /(\mathrm{Ch} 2+\mathrm{Ch} 1)$, where $\mathrm{Ch} 1$ and $\mathrm{Ch} 2$ are reflectance measured in the near infrared and red channels, respectively (Lillesand and Kiefer, 1994).

Furthermore, this index has been already applied for oak trees in some recent studies related with modelling the spectral reflectance of open cork oak woodland (Häusler et al., 2016). The regression tree model was applied to high-resolution remote sensing data for predicting the percentage of tree cover in a Mediterranean ecosystem (Donmez et al., 2015), analyzing aerial CIR images in forestry (Lehmann et al., 2015) and conducting dynamic analyses of ecological environments combined with land cover (Li et al., 2017). Land use modifications and phenological cycle of vegetation were explained due to anthropic effect (García-Mozo et al., 2016). Remote sensing applications by one parameter as NDVI and Aerobiology have interest with dispersal processes and ecological scaling (Gage et al., 1999). Also in phenological phenomena of Betula trees to establish the onset of flowering season (Hogda et al., 2002), predicting the onset of Betula pendula with thermal data (Bogawski et al., 2019), for forecasting land use phenology by short term data at real time sampling (White and Nemani, 2006) and to predict long time series of NDVI (Barbosa et al., 2006). Meteorological studies based on trends in vegetation dynamics and their relationship to rainfall (Barbosa et al., 2015) and air temperature (Lakshmi Kumar et al., 2013) were also studied. Among other applications of NDVI related with pollen have been produced a satellite map of start pollen season of Betula pollen grains (Karlsen et al., 2009) and for the identification of urban sources as the potential origin of Poaceae airborne pollen by geographic information system (Skjøth et al., 2013). Additionally, different landscapes can be analyzed considering the response of native and non-native bee species, such as Eucalyptus pollen foraging (Hilgert-Moreira et al., 2014) or the potential of detecting the maize pollen release stage, by using vegetation indices (Lu et al., 2015).

Climate change has been evaluated through plant phenology as an indicator of the response of ecosystems to the increase in temperature (García-Mozo et al., 2008; Ma et al., 2013; Parmesan and Yohe, 2003). Changes in the timing of flowering and the release of pollen grains from oak trees (Fernández-Rodríguez et al., 2016a; Grundström et al., 2019), cypresses (Silva-Palacios et al., 2016) and olives (FernándezRodríguez et al., 2016b) have been recorded in SW Europe. The relationships among the airborne pollen spectrum, pollination phenology, plant distribution and land cover modifications provoke alterations in the aerobiological content (Maya-Manzano et al., 2017). The relation between land cover influence and aerobiological data was analyzed (García-Mozo et al., 2016; Rojo and Pérez-Badia, 2015) with the identification of factors related to the emission sources (MayaManzano et al., 2016). Nevertheless, our understanding of the relationship between the distribution of pollen types and their sources of origin, which can often be difficult to identify, should be improved (MayaManzano et al., 2017).

In view of the effect of climate change (IPCC, 2017), forecasting is increasingly important, and it is necessary to use statistics (García-Mozo et al., 2016; García de León et al., 2015; Oteros et al., 2013). Several statistics are needed to correlate data, such as the pollen grains by the Granger causality test (Makra et al., 2016; Olchev et al., 2017) or the Spearman correlation test (Fernández-Rodríguez et al., 2016a; MayaManzano et al., 2016; Ríos et al., 2016; Uguz et al., 2017). NDVI has been correlated with Granger causality through several relationships, including vegetation and temperature (He et al., 2017), rainfall (He and Lee, 2016), local surface climate (Jiang et al., 2015), $\mathrm{CO}_{2}$ with global surface temperature (Leggett and Ball, 2014; Leggett and Ball, 2015), rainfall and land surface (Philippon et al., 2005), or phenology in grassland ecosystems (Zhu and Meng, 2014). The Granger causality consists in a statistical supposition test to decide if one time series is useful for forecasting another (Granger, 1969). To apply the test, it is necessary to select the number of delays or lags between the data of two time series.

Machine learning is a term used to define complex algorithms trying to replicate complex systems where the interactions between variables can be difficult to explain. They have increasingly been used in atmospheric science studies (Scheifinger et al., 2012). Due to its complexity sometimes can be difficult to understand (Astray et al., 2016). However, these state-of-the-art statistical techniques are capable of obtaining very high performances relevant to pollen modelling (Voukantsis et al., 2010). Among these techniques, the most commonly used has been the Artificial Neural Networks (thereafter ANN), particularly the Multi-Layer Perceptron approach because they are particularly tolerant with discontinuous sampling (missing data) in data collection periods (Puc, 2012). The input layer composes the first datasets to be introduced in ANN, and after that the processing is carried out by some hidden layers needed to generate the results (output layer) (Sánchez-Mesa et al., 2002). Some authors have reported performances using ANN, such as Puc (2012) with Betula, Astray et al. (2016) with Castanea or Csépe et al. (2014) trying to predict ragweed pollen concentrations.

Mediterranean forest-derived ecosystems in the SW Mediterranean region are mainly formed by tree species of oak (Quercus) (MayaManzano et al., 2016). These kind of trees occurs as in the studied area as "dehesas" forming rural landscape. Only in Extremadura oak trees occupy $1 / 3$ of the total area (Morillo and Espejo, 2008). To analyze the size and frequency distribution of polygons of land cover and trees maps is used the methodology of Potential Natural Vegetation (PNV) (Ibáñez and Gómez, 2016). Polygons are widely used to delimit space units for riparian vegetation (Wang et al., 2018) to assess the effects of different feature sets on land cover classification (Chen et al., 2018) and to correlate among the land uses and aerobiological airborne particles with dispersion patterns of air masses (Maya-Manzano et al., 2017). Other papers have studied the landscape pattern and its relationship with vegetation naturalness (Szilassi et al., 2017) and the response of land surface phenology to variation in tree cover during green-up and senescence periods (Cho et al., 2017). Furthermore, vegetation surveys using drone images and image analysis software (Han et al., 2017) and to address islands of biogeodiversity (Ibáñez et al., 2016) have recently been carried out. 
The advanced features in this aerobiological study are based in the innovation of remote sensing and the application of machine learning. Remote sensing data are important predictors in habitat types related to forests, rock outcrops and pastures. Ecological modelling by remote sensing have multiple advantages over traditional field surveys and image interpretation of habitat maps in time scale (Álvarez-Martínez et al., 2018). In order to forecast aerobiological data, ANN is being an important tool of different machine learning algorithms to work modelling complex data inputs of data as pollen concentration (Astray et al., 2016; Iglesias-Otero et al., 2015), for vegetation dynamic change simulations (Cai and Wang, 2010) and NDVI times series (Fernandes et al., 2017).

Our goal is to study the correlation among the NDVI related with oak trees included in three set data polygons $(15,25$ and $50 \mathrm{~km}$ to aerobiological sampling point as NDVI-15, 25 and 50), and oak (Quercus) daily average pollen counts from 1994 to 2013 in the SW Mediterranean region. Spearman correlation and Granger causality tests have been used to accomplish these goals. Moreover, a predictive model using ANN and testing the use of the different values of NDVI for each distance to the sampler was created as a first attempt to test the validity of this parameter (NDVI) as a forecasting tool.

\section{Materials and methods}

\subsection{Sampling site}

The studied city is placed in Badajoz (SW Mediterranean region). The analyzed area encompassed a diameter of 15, 25 and $50 \mathrm{~km}$ to aerobiological sampling point (Hirst, 1952) (Fig. 1). The areas were established by considering previous studies of Quercus pollen, such as Jato et al. (2002), which suggested adequate distances of 15 to $30 \mathrm{~km}$ based on the pollen in the air and the phenological stage of $Q$. robur and Q. pyrenaica. Other authors such as Hernández-Ceballos et al. (2015) suggested pollen transport distances of $40 \mathrm{~km}$, and most recently, Maya-Manzano et al. (2016) estimated transport values of up to $65 \mathrm{~km}$ as suitable.
The sampling point was located $\left(38^{\circ} 53^{\prime} 45^{\prime \prime} \mathrm{N}, 6^{\circ} 58^{\prime} 07^{\prime \prime} \mathrm{W}\right)$ at $6 \mathrm{~m}$ above ground level in the School of Agricultural Engineering belonging to the University of Extremadura, studying oak (Quercus) daily average pollen counts from 1994 to 2013. The adhesive petrolatum white (CAS number 8009-03-8) was used to capture airborne Quercus pollen, as in previous studies by Tormo-Molina et al. (2013) and Maya-Manzano et al. (2018). Standardized data procedures were followed as indicated by the Spanish Aerobiology Network (REA) (Galán et al., 2007).

Meteorological information (maximum and minimum temperature, mean temperature and rainfall for the previous ten days, and growing degree days, GDD, over $0{ }^{\circ} \mathrm{C}$ ) were supplied by the AEMET placed in the airport $\left(38^{\circ} 53^{\prime} \mathrm{N}, 6^{\circ} 49^{\prime} \mathrm{W}\right)$ during the period $1993-2000$ and from the university campus $\left(38^{\circ} 53^{\prime} \mathrm{N}, 7^{\circ} 00^{\prime} \mathrm{W}\right)$ for the period $2001-2013$.

\subsection{Satellite images of NDVI from NOAA/AVHRR}

Daily NDVI data (image files) were downloaded by the United States Geological Survey (USGS) from 1981 to 2013, on the website https:// earthexplorer.usgs.gov/. These images have $1 \mathrm{~km}$ of nominal spatial resolution (depending on the angle of view of the satellite) that have been resampled at $1 \mathrm{~km}^{2}$. Additionally, maximum search algorithms have been applied for the elimination of cloud cover. NDVI values from the corrected data are stored in a separate channel (Eidenshink and Faundeen, 1994), as well as Projection Goode Homolosine (Goode, 1925), radiometric and geometric corrections and the width of the image (approximately $2700 \mathrm{~km}$ ). The pixel info of the images is scaled to 10,000 . Therefore, to obtain the real NDVI values, it is necessary to multiply them by a scale factor of 0.0001 .

In order to analyze the NDVI images, they were compared with the days of the Oak (Quercus) Main Pollen Season (MPS) from 1994 to 2013, estimated by Fernández-Rodríguez et al. (2016a). Based on the MPS of each year, a dataset of 1279 NDVI images was studied by extracting the values of the vegetation index in the three training areas.
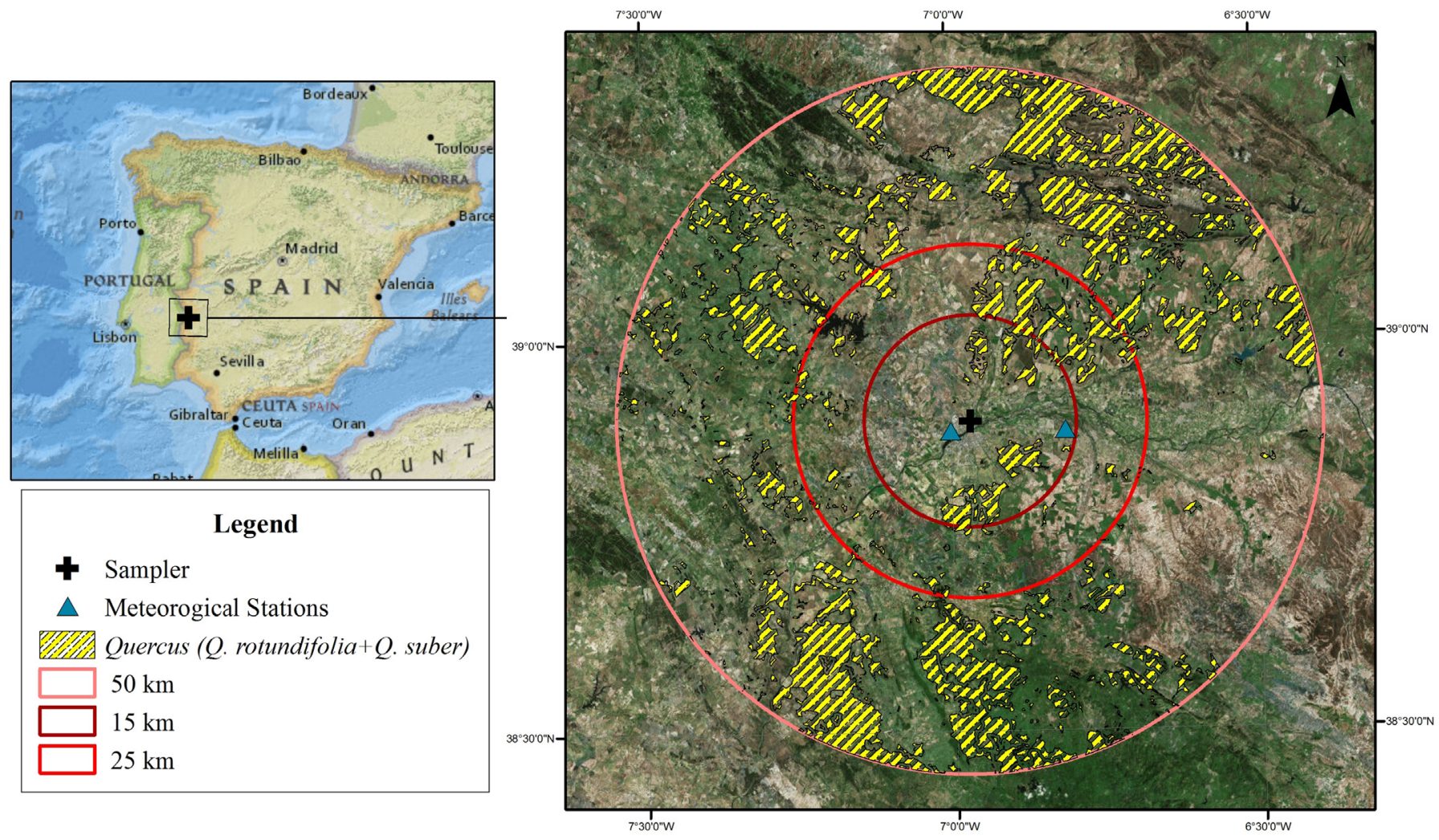

Fig. 1. Study area. 


\subsection{Cartography}

The analyzed area includes two regions, Extremadura in Spain and Alentejo in Portugal, of the SW Mediterranean region. For this reason, the Extremadura Forest Map (MFEx) and data from the Fifth National Forest Inventory of Portugal (IFN5), related with oak trees, were used. Autoridade Forestal Nacional (AFN) (2010) supplied IFN5 information from National Forest Inventory 2005-06, Continental Portugal-IFN5 2005-06. The polygons containing the vegetation (oak trees) under study were extracted from the MFEx and the IFN5, and to avoid the possible georeferencing misalignments of the different data sources, inner buffers of $200 \mathrm{~m}$ were achieved. To establish the distribution of Quercus within each one of the study areas, one intersection of those polygons and three circumferences of 15, 25 and $50 \mathrm{~km}$-distance around the volumetric sampler were performed, and the NDVI values for each MPS day were extracted (Fig. 1).

The training area located $15 \mathrm{~km}$ around the sampler contained 25 polygons with oak trees with a total area of $227.01 \mathrm{~km}^{2}$. For the area approximately $25 \mathrm{~km}$ from the sampler, 69 polygons in an area of $433.58 \mathrm{~km}^{2}$ were studied. Finally, covering the total training area of $50 \mathrm{~km}, 268$ polygons that entail an area of $2598.60 \mathrm{~km}^{2}$ were evaluated. Lastly, a graphic representation of both time series (NDVI values and pollen concentration) was created to establish the correspondence between them (Fig. 2).

\subsection{Statistical analysis}

The relationship between oak (Quercus) pollen concentration and NDVI was evaluated by the Spearman and the Granger causality test. The objective of the latter test was to determine if one variable $X$ causes another variable $Y$. Once the variables $X$ and $Y$ are defined, the regression of the endogenous variable $Y_{t}$ on its own past, that is, $Y_{t-1}, Y_{t-2}$, $\mathrm{Y}_{\mathrm{t}-3}$; on the variable $\mathrm{X}_{\mathrm{t}}$ a series of delayed values of the same, that is, $\mathrm{X}_{\mathrm{t}-1}, \mathrm{X}_{\mathrm{t}-2}, \mathrm{X}_{\mathrm{t}-3}$, etc. Once this regression is done, it is determined if it is easier to predict the future of the variable $Y$ with this instrument or if it would be easier to estimate $Y_{t}$ exclusively using the function of its past without knowing its relation with X. In other words, it is analyzed if the current $X$ variable and past provides valuable information to explain the future of $Y$ (it is said, in that case, that $X$ is the Granger cause of $\mathrm{Y}$ ).

In this study, this Granger causality test aimed to test if there is causality between NDVI and the oak (Quercus) airborne pollen concentration within the studied areas. If NDVI behaves as a predictor of pollen concentration, then NDVI becomes the causal Granger for oak (Quercus) pollen concentrations. A crucial aspect for the causality test is to determine the number of delays or lags between the two time series with which the prediction can be ensured. The lag is important for a suitable forecasting, and its determination can be tested by different decision criteria such as FPE: final prediction error; AIC: Akaike information criterion; SC: Schwarz information criterion; or HQ: Hannan-Quinn information criterion. AIC is the most commonly used estimator for this determination. On basis to the set of the model data, AIC calculates the quality of each model in relation to the rest of the other models (Akaike, 1978; Akaike, 1979; Akaike, 1987). Initially, the study of several lags must be attained between the time series of each year, and via the AIC, the best one must be selected. The AIC statistic has been used to analyze the fit among forecast models. AIC model with lower value has a suitable fit to the observed data and a better model performance (Taghipour Javi et al., 2014). Some studies as Huang et al. (2010) and Jing et al. (2014), have utilized the AIC to estimate the correlation of NDVI data for modelling and prediction of crop canopy coverage (Ottosen et al., 2019).

The relationship between oak (Quercus) pollen concentrations and different meteorological parameters (maximum and minimum temperature, mean temperature and rainfall for the previous ten days, wind speed and growing degree days, GDD, over $0{ }^{\circ} \mathrm{C}$ ) and NDVI values (NDVI50, NDVI25, NDVI15) was evaluated and modelled by ANN analysis (Zhang Guoqiang et al., 1998), to predict Quercus pollen. To do it, the package "neuralnet" in R software (Team, 2014) has been used. Data normalization (in our case from 0 to 1 ) was performed before the training process in order to avoid computational problems (Lapedes and Farber, 1988), according to the specifications in the mentioned package. The $70 \%$ of data were used to train the model, and the remaining $30 \%$ for validation. After the validation, the results were rescaled. The ANN model with the lowest RMSE (root mean square error) was chosen after optimization for the different NDVI combinations under evaluation. Later, according to the AIC index, we chose those lags days with better results (3, 4 and 5 days) belonging to this training area (NDVI25), and all of them were compared depending again on the RMSE. Spearman rho's rank is also shown for the chosen one. Thus, for NDVI25 the optimal lag day was 5 days.

\section{Results}

\subsection{Time series}

The average of NDVI values within the three training areas for each day of the MPS were calculated and represented. This time series, NDVI 15 km, NDVI $25 \mathrm{~km}$ and NDVI $50 \mathrm{~km}$ (Fig. 2), was correlated

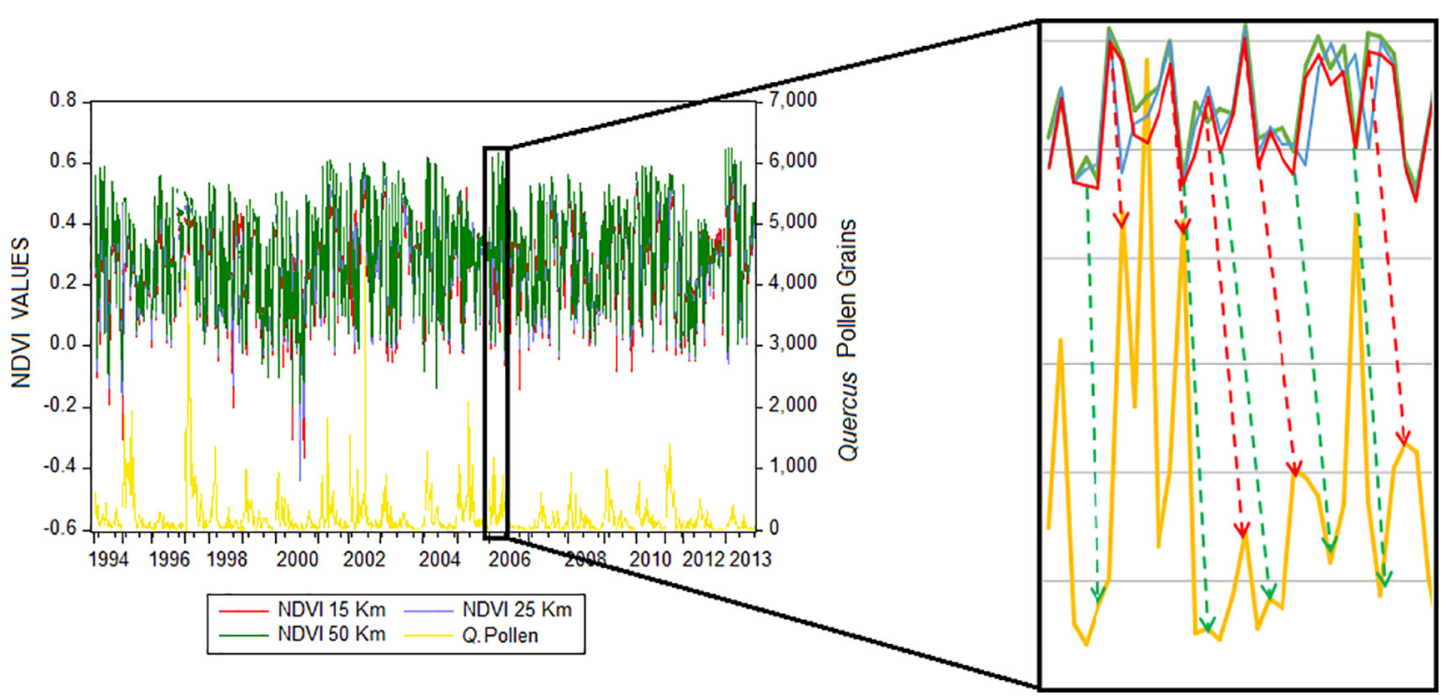

Fig. 2. NDVI and airborne pollen concentration time series. Negative values of NDVI come from wet soil caused by rain before the date of acquisition of the satellite imagery. 
with airborne pollen concentration during the MPS from 1994 to 2013. From the visual analysis of the matching between time series, peaks of NDVI that predicted peaks of Quercus can be detected. Fig. 2 shows in 2006, the maximum and minimum peaks of NDVI precede the maximum and minimum peaks of pollen concentration.

\subsection{Determination of lags}

Based on the AIC, the optimum lags between time series were determined. As shown in Table 1, the value is not constant but ranges from only 1 day (years 1996, 1997, 1999, 2002 and 2011) up to 13 days in 2007 and 2012.

\subsection{Statistical analysis}

The correlation was statistically studied using the Spearman test and the Granger causality test. The results forthcoming from the Spearman correlation test (Table 1) show that 1996, 1999 and 2012 had nonsignificant correlations with pollen concentration within the three training areas. Additionally, years 1994, 2000 and 2006 had few significant correlations in only one training area, with substantial dispersions in the other training areas. Fig. 3a-d, the percentage of modification between consecutive data of pollen time series versus the percentage of change of the mean NDVI within the three training areas is represented. The graphs underwrite the Spearman correlation results for those years. More dispersion in the graphs generally means low values in the Spearman correlation, as in 1996, 1999 and 2000. On the other hand, 1995, 1997 and 2001, with correlations, present slightly scattered graphs.

$45 \%$ of the years $(1994,1996,1999,2003,2006,2008,2010,2011$ and 2012) had significant results in the Granger causality test in all training areas (Table 1), and 2000 and 2013 had significant results in two of the training areas. As can be appreciated, only 2003, 2008 and 2011 had significant values of positive correlation and causality in the three study areas, but there is no year with no correlation and causality significance.

Focusing on the yearly results, there are two years with significant values of positive correlation in some of the study areas where there are no significant results of causality. In particular, in 2000, there were significant correlation values in the $25 \mathrm{~km}$ zone around the collector and significant causality results in the 50 and $15 \mathrm{~km}$ zones, and in 2006, there was significant correlation at $50 \mathrm{~km}$ and significant causality at $25 \mathrm{~km}$. Similarly, on four occasions, there was a significant positive correlation in all areas of study and significant causality in only some of them. For example, in the years 2004 and 2007, there was significant causality only in the $50 \mathrm{~km}$ area, but there was correlation in all training areas. In the same way, for the year 2005, significant causality occurred only within the $15 \mathrm{~km}$ zone, and in 2009, there was significant causality at 50 and $25 \mathrm{~km}$ around the measuring station. Finally, two years (2010 and 2013) had significant values of causality within the three areas of study and significant correlation in only some of them.

According to the RMSE values (Table 2), the ANN model containing all the NDVI values showed slightly better results than the one without values of NDVI. The fact that all together did not show comparatively as good results as by separate, it can be due to the addition of some correlated variables can cause multicollinearity and can mask the interactions (Yu et al., 2015). NDVI25 obtained better results than those considering NDVI25 and NDVI50, not only by separate but also by groups. The better result was the model by using only NDVI25 values. Due to the results obtained were quite similar between the model with NDVI25 and the model with NDVI_lag5, obtaining the second slightly higher error, it was finally selected. It is because, to introduce the NDVI_lag5 allows to predict for 5 days in advance, due to we can obtain 5 different values from the lag day to the present day, plus the forecasted weather, instead of only one (if we used NDVI25). Only seven different parameters were needed to performance the model, and all the weather parameters are easy to obtain. The final structure for our ANN model showed a layer's structure of 6:8:4:1, which is shown in Fig. 4. Fig. 5 shows the difference between observed and predicted values for the validation subset.

\section{Discussion}

NDVI has been used to correlate pollen grain release (such as Poaceae pollen) of one cultivation as maize, indicating that the time most suitable for this relationship is the flowering stage (Lu et al., 2015). This work studied whether variations in the NDVI can precede variations in the accumulation of pollen in the atmosphere. Until this work, there were no studies demonstrating this premise. However, the opposite assertion has been established in the mentioned study. In this way, it has been demonstrated that after the release of pollen grains, the value of NDVI decreased. This could be caused by the reflectance in the visible and near-infrared wavelengths decreasing once the pollen release begins. The NDVI decreases from the day when the maximum concentration of pollen is reached (Lu et al., 2015). Moreover, this

Table 1

Statistical test results within the three training areas (significant correlations in bold).

\begin{tabular}{|c|c|c|c|c|c|c|c|c|c|c|}
\hline \multirow[t]{2}{*}{ Year } & \multirow[t]{2}{*}{ LAGS } & \multicolumn{3}{|l|}{$50 \mathrm{~km}$} & \multicolumn{3}{|l|}{$25 \mathrm{~km}$} & \multicolumn{3}{|l|}{$15 \mathrm{~km}$} \\
\hline & & $\begin{array}{l}\text { Spearman } \\
\text { correlation }\end{array}$ & $\begin{array}{l}\text { Spearman } \\
\text { p-value }\end{array}$ & $\begin{array}{l}\text { Granger } \\
\text { p-value }\end{array}$ & $\begin{array}{l}\text { Spearman } \\
\text { correlation }\end{array}$ & $\begin{array}{l}\text { Spearman } \\
\text { p-value }\end{array}$ & $\begin{array}{l}\text { Granger } \\
\text { p-value }\end{array}$ & $\begin{array}{l}\text { Spearman } \\
\text { correlation }\end{array}$ & $\begin{array}{l}\text { Spearman } \\
\text { p-value }\end{array}$ & $\begin{array}{l}\text { Granger } \\
\text { p-value }\end{array}$ \\
\hline 1994 & 9 & 0.3510 & 0.0080 & 0.0092 & 0.3220 & 0.0160 & 0.0038 & 0.3120 & 0.0190 & 0.0460 \\
\hline 1995 & 8 & 0.5320 & $<0,0001$ & 0.6798 & 0.3490 & 0.0100 & 0.9318 & 0.2870 & 0.0360 & 0.7063 \\
\hline 1996 & 1 & 0.2070 & 0.1380 & 0.0350 & 0.1920 & 0.1690 & 0.0462 & 0.1450 & 0.3000 & 0.0448 \\
\hline 1997 & 1 & 0.5930 & $<\mathbf{0 , 0 0 0 1}$ & 0.1400 & 0.6340 & $<\mathbf{0 , 0 0 0 1}$ & 0.1300 & 0.5760 & $<\mathbf{0 , 0 0 0 1}$ & 0.1500 \\
\hline 1998 & 10 & 0.3910 & 0.0010 & 0.5200 & 0.3810 & 0.0020 & 0.6000 & 0.0970 & 0.4390 & 0.0300 \\
\hline 1999 & 1 & 0.0900 & 0.5200 & 0.0290 & 0.1480 & 0.2890 & 0.0242 & 0.0830 & 0.5550 & 0.0086 \\
\hline 2000 & 12 & 0.2170 & 0.1040 & 0.0009 & 0.2200 & 0.0460 & 0.2013 & 0.1480 & 0.2710 & 0.0464 \\
\hline 2001 & 4 & 0.5210 & $<\mathbf{0 , 0 0 0 1}$ & 0.0509 & 0.5060 & $<\mathbf{0 , 0 0 0 1}$ & 0.1110 & 0.5000 & $<\mathbf{0 , 0 0 0 1}$ & 0.0900 \\
\hline 2002 & 1 & 0.4280 & 0.0010 & 0.0800 & 0.5330 & $<\mathbf{0 , 0 0 0 1}$ & 0.1100 & 0.3940 & 0.0020 & 0.1100 \\
\hline 2003 & 11 & 0.3060 & 0.0060 & 0.0428 & 0.3000 & 0.0070 & 0.0321 & 0.2550 & 0.0220 & 0.0363 \\
\hline 2004 & 4 & 0.2820 & 0.0410 & 0.0445 & 0.4060 & 0.0030 & 0.2096 & 0.3570 & 0.0090 & 0.1793 \\
\hline 2005 & 12 & 0.4820 & 0.0000 & 0.2796 & 0.5210 & $<\mathbf{0 , 0 0 0 1}$ & 0.2038 & 0.3510 & 0.0060 & 0.0495 \\
\hline 2006 & 15 & 0.2290 & 0.0470 & 0.3960 & 0.1080 & 0.3510 & 0.0290 & 0.1030 & 0.3770 & 0.2510 \\
\hline 2007 & 13 & 0.3190 & 0.0060 & 0.0400 & 0.3370 & 0.0040 & 0.0600 & 0.3220 & 0.0060 & 0.1400 \\
\hline 2008 & 7 & 0.4370 & 0.0010 & 0.0149 & 0.4400 & 0.0010 & 0.0077 & 0.4160 & 0.0020 & 0.0094 \\
\hline 2009 & 6 & 0.2570 & 0.0460 & 0.0150 & 0.2580 & 0.0450 & 0.0310 & 0.2800 & 0.0290 & 0.0900 \\
\hline 2010 & 9 & 0.2520 & 0.0620 & 0.0400 & 0.3260 & 0.0150 & 0.0300 & 0.3500 & 0.0080 & 0.0400 \\
\hline 2011 & 1 & 0.6080 & 0.0000 & 0.0209 & 0.6060 & 0.0000 & 0.0176 & 0.5950 & 0.0000 & 0.0038 \\
\hline 2012 & 13 & 0.0350 & 0.7580 & 0.0045 & -0.0480 & 0.6740 & 0.0153 & -0.2030 & 0.0720 & 0.0189 \\
\hline 2013 & 9 & 0.4690 & 0.0000 & 0.2400 & 0.4790 & 0.0000 & 0.0360 & 0.4490 & 0.0010 & 0.0217 \\
\hline
\end{tabular}



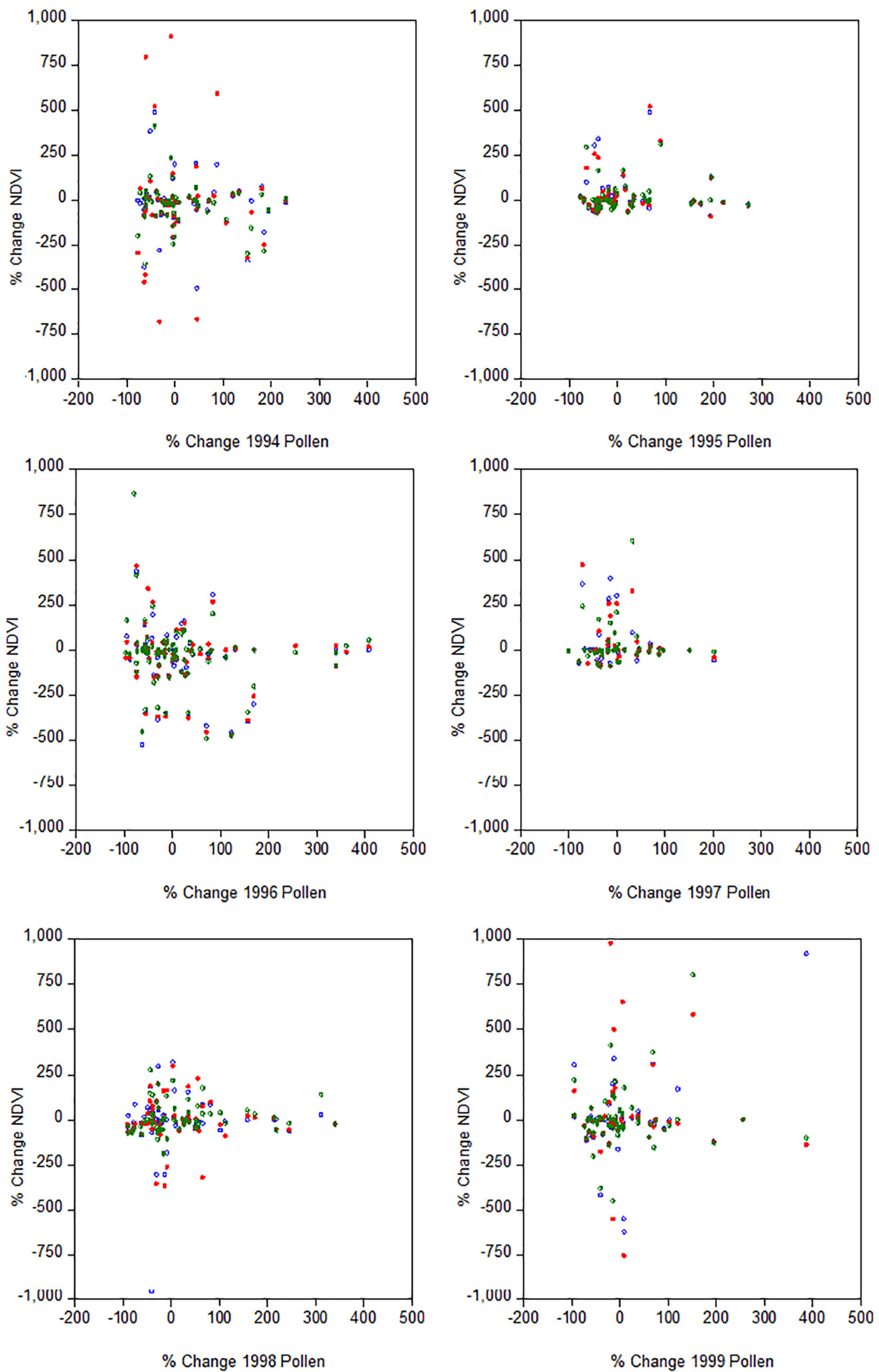

\footnotetext{
。 \% Change NDVI $15 \mathrm{~km}$

\% Change NDVI $25 \mathrm{~km}$

$\%$ Change NDVI $50 \mathrm{~km}$
} 

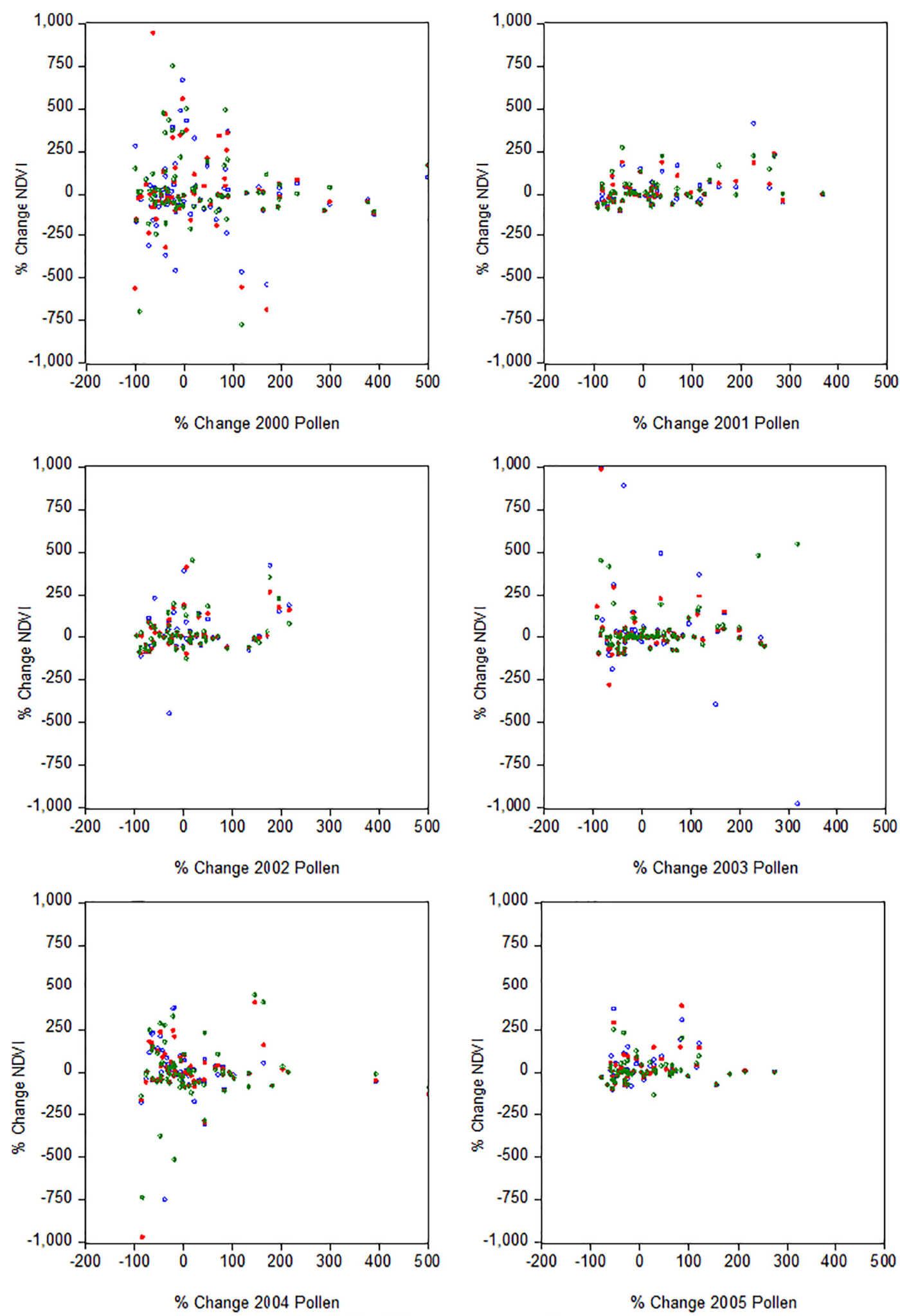

- \% Change NDVI $15 \mathrm{~km}$

- \% Change NDVI $25 \mathrm{~km}$

- \% Change NDVI $50 \mathrm{~km}$

index was applied for determining the start dates of birch pollen seasons over 18 years (Hogda et al., 2002). In this way, we have studied 1279 days over 20 years, which is a longer period than in other studies. Furthermore, NDVI has been used for phenological studies on species such as oak trees (Liu et al., 2017) or birches, by the onset flowering for 8 years (Karlsen et al., 2009), the length of the growing season for
7 years (Karlsen et al., 2008) and the onset of phenological phases (Karlsen et al., 2006) for 20 years.

Focusing on our results, the maximum correlation between NDVI and airborne Quercus pollen MPS for the studied period and three training area zones varied between 0.63 and 0.59. Lu et al. (2015) obtained a correlation $\left(\mathrm{R}^{2}=0,26\right.$ for NDVI) among the vegetation index at the red 

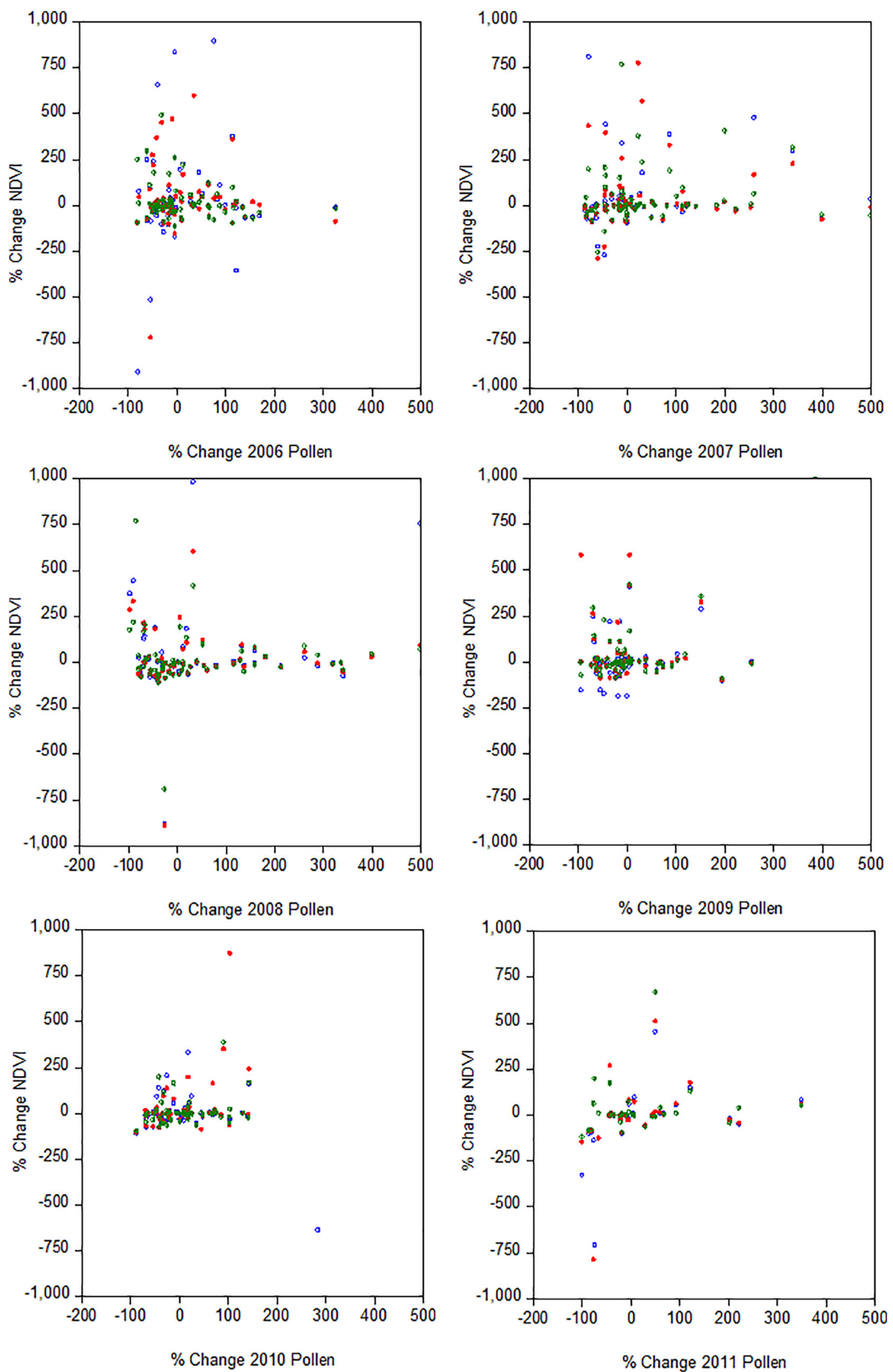

\footnotetext{
- \% Change NDVI $15 \mathrm{~km}$

- \% Change NDVI $25 \mathrm{~km}$

- \% Change NDVI $50 \mathrm{~km}$
} 


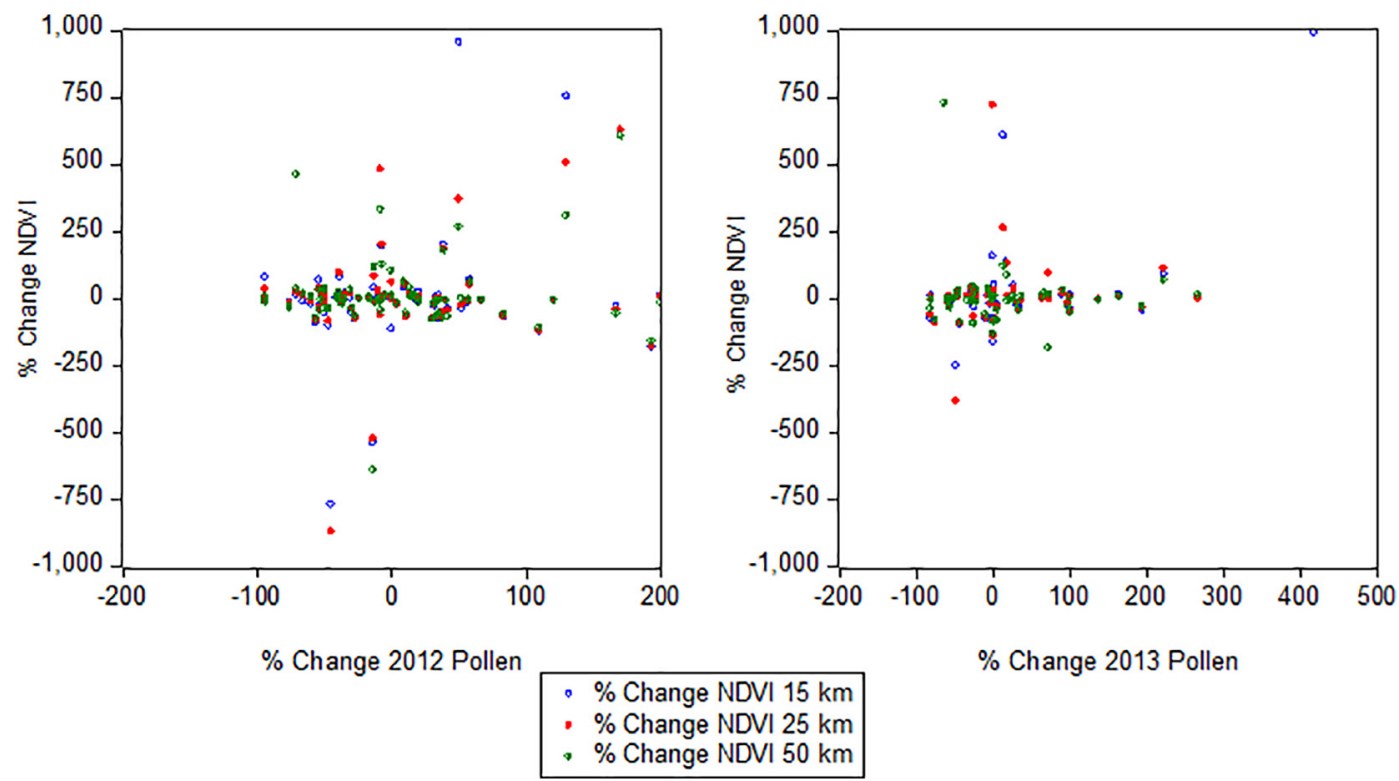

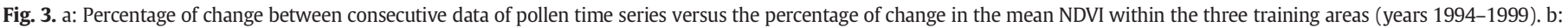

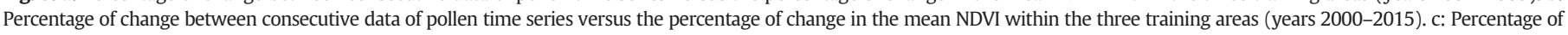

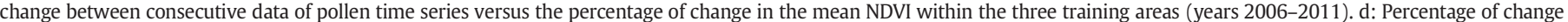
between consecutive data of pollen time series versus the percentage of change in the mean NDVI within the three training areas (years 2012-2013).

edge and 2-day average maize pollen. He et al. (2017) correlated linear trends of growing season NDVI and temperature, obtaining values of $\mathrm{R}^{2}$ between 0.44 and 0.01 . In this study, the distances of influence on the contribution of oak (Quercus) pollen to the sampler have shown statistically significant results depending on the year studied. In the same way, the number of days of NDVI that can predict values that will be recorded in the sampler varies depending on the year (from 13 days in 2007 and 2012 to 1 day in 1996, 1999 and 2000). Several works indicated results in this line. White and Nemani (2006) showed that a hypothetical land surface phenology event could be predicted with a leadtime of 7 days for an allowable prediction uncertainty of 2 days. For Karlsen et al. (2006), the onset of the growing season in the NDVIbased measurements is tuned to occur, on average, $<2$ days before the onset of leafing. The standard deviation (SD) between field data and NDVI data is $<10$ days for all stations.

The relationship between distant sources of oak trees and the sampler point has been explained by the long distance transport (LDT) for Quercus pollen in the UK (Skjøth et al., 2015) and Spain, such as in Andalucía (Hernández-Ceballos et al., 2011) or Extremadura (Maya-Manzano et al., 2016). The last authors estimated the closest sources of airborne Quercus pollen in $40 \mathrm{~km}$ (Plasencia-North Ex), 66 km (Don Benito- Middle Ex), and $62 \mathrm{~km}$ (Zafra-South Ex). In the same region, Maya-Manzano et al. (2017) reported also a medium-long transport behaviour for this pollen type. These results agreed with the maximum predictive power observed for the current study at medium and long distance transport (being better for NDVI25). Among all the combinations that were studied, the combination between NDVI50 and NDVI25 was also the one with the most predictive capability. In this work, we have studied the regional scale $(50,25$ and $15 \mathrm{~km})$ up to a $100 \mathrm{~km}$ limit to consider a wide range of potential sources (Seinfeld and Pandis, 2006). The importance of the relation between the distribution of the oak trees and the distance to the trap was studied in Spanish urban areas, such as Badajoz and Córdoba (Fernández-Rodríguez et al., 2014b; Velasco-Jiménez et al., 2013). The idea of the present study is to analyze, with detail, the influence of short and medium-distance sources (local urban, surrounding urban and far away urban) on the regional scale and the relationship with NDVI to improve future forecasting of Quercus pollen concentrations (Fernández-Rodríguez et al., 2016a). Also the wind speed has been proposed as having great importance by Maya-Manzano et al. (2016), who reported an increase in the Quercus concentrations in wind speed range from 6 to $10 \mathrm{~m} \mathrm{~s}^{-1}$, in the same region of study. In the same way, the wind direction is important, because the sources are playing an important role in the airborne content and the oak forests are heterogeneously dispersed along the territory. Moreover, wind direction pattern can overestimate concentration if sources are in the line of the predominant wind direction pattern. However, the lack of records for this parameter during a part of the studied period made impossible to include it in the model.

The use of polygons for delimiting soil and vegetation was created by several methodologies. Nevertheless, considering the number and size of the polygons for mapping, both fit well to power laws across several orders of magnitude, showing that both exhibit a scale invariance pattern (Ibáñez et al., 2016). In the Ibáñez study, totals of 5864

Table 2

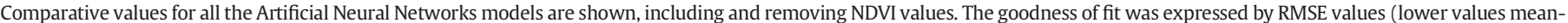

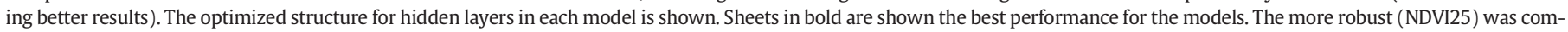
pared with other by adding the Lag 5 days.

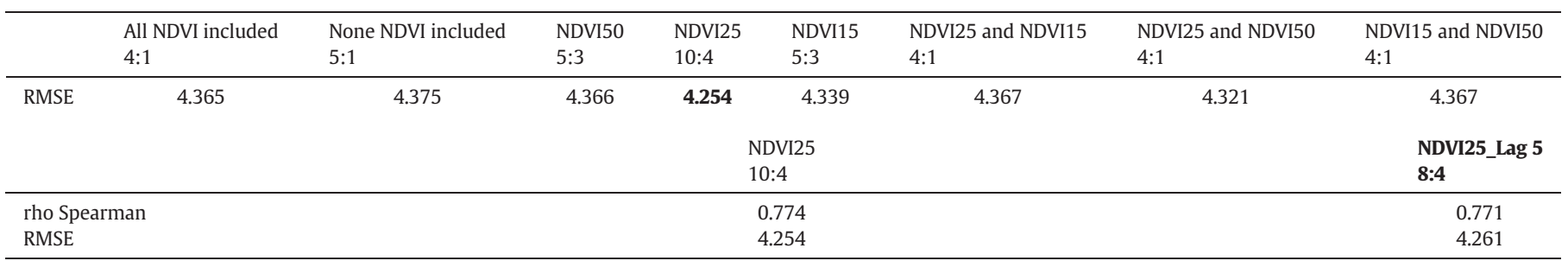




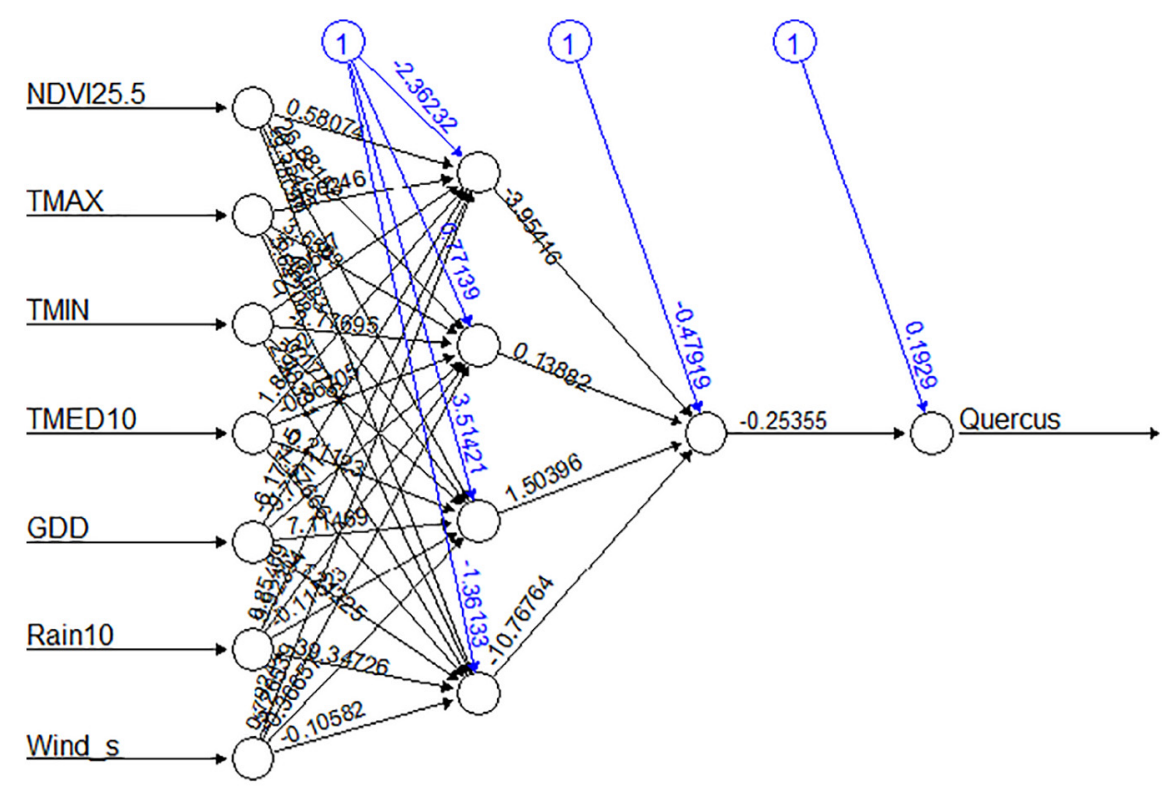

Error: 1.291676 Steps: 421

Fig. 4. Artificial Neural Network for the model proposed (Including NDVI25_lag5).

$(1: 10,000)$ and $2448(1: 100,000)$ polygons were created for potential vegetation analysis and soil associations, respectively, in the Almería province $\left(8775 \mathrm{~km}^{2}\right)$. The proportion of our study is similar with a maximum total training area of $50 \mathrm{~km}\left(7853 \mathrm{~km}^{2}\right)$ located in Badajoz and Alentejo provinces. Inside this area, we have studied 268 polygons of Quercus spp. covering an area of $2598 \mathrm{~km}^{2}$. Cho et al. (2017) produced 100 polygons to determine the influence of varying tree cover, and Wang et al. (2018) created 106,300 vegetation polygons in a reach of the Sacramento River, USA, for five major vegetation types (cottonwood, mixed forest, riparian shrub, invasive species and grass) simulated in 20 vegetation species. (Szilassi et al., 2017) studied 40,000 CLC polygon categories for class-level analyses of the landscape pattern (artificial surfaces, agricultural areas, forest and semi natural areas, wetlands and water bodies).

According to the range of years, in all years of this study (except 1996 and 1999, in which significant results were not obtained for the Spearman test), there is a statistically significant positive correlation. However, 2012 showed a negative correlation. He et al. (2017) found negative correlations between NDVI and vegetation growth for several

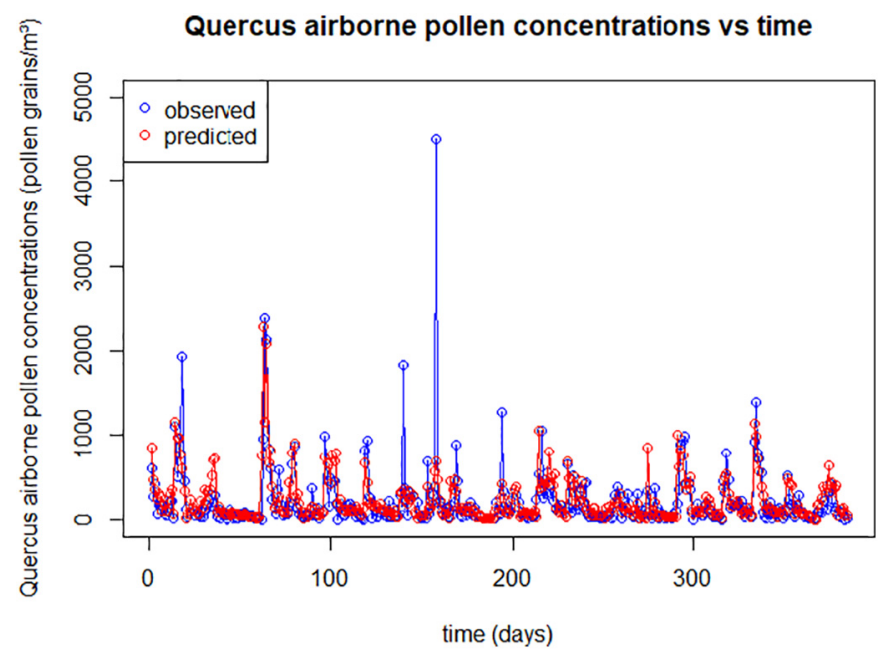

Fig. 5. Observed vs. predicted values obtained by the ANN model $(r=0.77)$. years (1998-2011) of their study. They explained this fact by the sensitivity of vegetation growth to temperature change. We found 14 years with statistically significant results using the Granger causality test (1994, 1996, 1999, 2000 and 2003-2013). Among those years with significant results using the Granger test, there is no significant correlation between NDVI and vegetation growth in 1996, 1999 and 2012. Therefore, for these years, it cannot be said that the NDVI that was measured in the different study areas behaves as a predictor of the pollen concentration recorded in the sampler.

If we consider the distance, approximately $50 \mathrm{~km}$, to the sampler, in 2004 and 2007, there was significant causality. For these years, it can be affirmed with a $95 \%$ probability of success that the NDVI measured in the study area located $50 \mathrm{~km}$ around the collector is a predictor of the amount of pollen recorded in it. In 2004, a rise in the value of the NDVI predicted increases for pollen that were recorded 4 days later in the collector, while in 2007, the prediction was made 13 days in advance.

In 2005, a significant causality occurred in the $15 \mathrm{~km}$ zone, and NDVI predicted increases for pollen 12 days later in the sampler. Likewise, in 2009, there was significant causality at 50 and $25 \mathrm{~km}$ around the sampler with increases in the NDVI, having predicted increases in oak (Quercus) pollen concentration 6 days later in the sampler. In 2010 and 2013, there was only a significant positive correlation in the areas of 25 and $15 \mathrm{~km}$. In these zones, the NDVI is the Granger cause of the concentration of pollen registered in the sampler. The main contribution to the pollen collected in the sampler comes from the production sources located at short and medium distances (15 and $25 \mathrm{~km}$ ). For both years, rises in the NDVI have predicted increases in pollen recorded in the collector 9 days later. On four occasions (1994, 2003, 2008 and 2011), there were significant values of positive correlation and causality in the three study areas with increases in the NDVI predicted $(9,11,7$ and 1 days later, respectively) over sources located at short, medium and long distance $(15,25$ and $50 \mathrm{~km})$. Finally, in five years (1995, 1997, 1998, 2001 and 2002), significant values of causality were not found, but a positive correlation in the three study areas was. Therefore, in these years, the NDVI and pollen variables were positively related to each other, but it cannot be affirmed that the NDVI can be a predictor of the concentration of pollen registered in the sampler.

Consequently, we assume that temporal correlations between years and spatial correlations of several distances between the NDVI values of oak trees (Fernández-Martínez et al., 2012; Pinto et al., 2011) and the 
concentration of airborne oak (Quercus) pollen are influenced by meteorology (García-Mozo et al., 2012; García-Mozo et al., 2007). Moreover, it should be noted that Spearman correlation and Granger causality tests require checking whether the results of one variable serve to predict another one and whether this relationship is unidirectional or bidirectional. Therefore, we have studied two variables, NDVI and pollen concentration; however, new related reports should contemplate additional statistical analyses, including those of meteorological data (considering parameters such as temperature and accumulative temperature, rainfall and wind or even sunlight hours, which influence phenology). Moreover, it would be interesting to study other pollen types such as Olea or Poaceae pollen, which are, together with Quercus pollen, the most represented and abundant of Extremadura and Alentejo in the SW Iberian Peninsula (Fernández-Rodríguez et al., 2015; FernándezRodríguez et al., 2016a; Fernández-Rodríguez et al., 2014a). The novelty of this study includes the positive role of big data analysis in ecological environmental change and natural management, specifically related to land cover and NDVI change trend analysis. In this way, future studies could be designed as local responses to activities and ecological changes at several scales, being in line with Li et al. (2017). The use of available satellite data, such as NDVI, together with pollen grain sampling, meteorological and phenological data (Bogawski et al., 2019), has been proposed as a powerful tool to be used with aerobiological purposes (Scheifinger et al., 2012). It should allow a quick information at realtime monitoring, predicting short-term data of oak (Quercus) pollen concentration to be implemented (Fernández-Rodríguez et al., 2016a).

\section{Conclusions}

The innovation in this article is the relationship among the NDVI value of oak trees ( $Q$. rotundifolia and $Q$. suber) over several distances; local urban (15 km), surrounding urban (25 km) and far away urban (50 km), with oak pollen count daily average from 1994 to 2013 in the SW Mediterranean region, by Spearman and Granger causality tests. Also the creation of one predictive analysis by using ANN models, with a $r=0.77$ and a forecast horizon of 5 days, applying the 5 days-lag for NDVI25. Of the 20 studied years, 9 showed a significant relationship between NDVI and pollen concentration with the Granger causality test, while there were showed significant values in 12 years by Spearman test.

The distances of influence on the contribution of oak (Quercus) pollen to the sampler showed statistically significant results depending on the year studied. In the same way, the number of days that NDVI values can predict recorded values of pollen concentration in the sampler ranged depending on the year (from 13 days in 2007 and 2012 to 1 day in 1996, 1999 and 2000). The number of years with significant correlations obtained within $50 \mathrm{~km}$ and $25 \mathrm{~km}$ was similar, but within $15 \mathrm{~km}$, the number decreased slightly, and it may be in relation to a lower abundance of trees closer to the urban area. It agreed with the findings regarding the forecast capacity for the different NDVI indexes in the ANN model. It could be explained the variability among years due to the influence of local meteorology, including the effect of far away air masses with aerobiological particles from potential sources. For this assumption, new studies should be considered phenological data, additional statistical analysis, more pollen types in order to get quick information at real-time monitoring, predicting short-term data aerobiological information.

\section{Acknowledgements}

This work was possible by funds from research projects PRI-IB16029 and research groups aid GR15060 financed by the Regional Government, Junta de Extremadura (Spain) and the European Regional Development Fund. Particularly, Irish Environmental Protection Agency (EPA), by means of a Research Fellowship (programme 2014-2020, Climate, 2017), funds to J.M.M.M. The authors want to thank the support of
LTER Montado site (LTER Portugal network) for the contribution of cartographic data of the Fifth National Forest Inventory of Portugal (IFN5) concerning oak and cork oak locations.

\section{References}

Akaike, H., 1978. On the likelihood of a time series model. J. R. Stat. Soc. Ser. D (The Statistician) 27, 217-235

Akaike, H., 1979. A Bayesian extension of the minimum AIC procedure of autoregressive model fitting. Biometrika 66, 237-242.

Akaike, H., 1987. Factor analysis and AIC. Psychometrika 52, 317-332.

Álvarez-Martínez, J.M., Jiménez-Alfaro, B., Barquín, J., Ondiviela, B., Recio, M., SilióCalzada, A., et al., 2018. Modelling the area of occupancy of habitat types with remote sensing. Methods Ecol. Evol. 9, 580-593.

Astray, G., Fernández-González, M., Rodríguez-Rajo, F.J., López, D., Mejuto, J.C., 2016. Airborne castanea pollen forecasting model for ecological and allergological implementation. Sci. Total Environ. 548-549, 110-121.

Barbosa, H.A., Huete, A.R., Baethgen, W.E., 2006. A 20-year study of NDVI variability over the Northeast Region of Brazil. J. Arid Environ. 67, 288-307.

Barbosa, H.A., Lakshmi Kumar, T.V., Silva, L.R.M., 2015. Recent trends in vegetation dynamics in the South America and their relationship to rainfall. Nat. Hazards 77, 883-899.

de Beurs, K.M., Henebry, G.M., 2004. Land surface phenology, climatic variation, and institutional change: analyzing agricultural land cover change in Kazakhstan. Remote Sens. Environ. 89, 497-509.

Bogawski, P., Grewling, Ł., Jackowiak, B., 2019. Predicting the onset of Betula pendula flowering in Poznań (Poland) using remote sensing thermal data. Sci. Total Environ. 658, 1485-1499.

Cai, Z., Wang, X., 2010. Research on vegetation dynamic change simulation based on spatial data mining of ANN-CA model using time series of remote sensing images. IFIP Adv. Inf. Commun. Technol. 317, 551-557.

Chen, W., Li, X., He, H., Wang, L., 2018. Assessing different feature sets' effects on land cover classification in complex surface-mined landscapes by ZiYuan-3 satellite imagery. Remote Sens. 10.

Cho, M.A., Ramoelo, A., Dziba, L., 2017. Response of land surface phenology to variation in tree cover during green-up and senescence periods in the semi-arid savanna of Southern Africa. Remote Sens. 9.

Csépe, Z., Makra, L., Voukantsis, D., Matyasovszky, I., Tusnády, G., Karatzas, K., et al., 2014). Predicting daily ragweed pollen concentrations using Computational Intelligence techniques over two heavily polluted areas in Europe. Sci. Total Environ. 476-477, $542-552$.

Donmez, C., Berberoglu, S., Erdogan, M.A., Tanriover, A.A., Cilek, A., 2015. Response of the regression tree model to high resolution remote sensing data for predicting percent tree cover in a Mediterranean ecosystem. Environ. Monit. Assess. 187.

Eidenshink, J.C., Faundeen, J.L., 1994. The 1 km AVHRR global land data set: first stages in implementation. Int. J. Remote Sens. 15, 3443-3462.

Fernandes, J.L., Ebecken, N.F.F., Esquerdo, J.C.D.M., 2017. Sugarcane yield prediction in Brazil using NDVI time series and neural networks ensemble. Int. J. Remote Sens. $38,4631-4644$.

Fernández-Martínez, M., Belmonte, J., Maria Espelta, J., 2012. Masting in oaks: disentangling the effect of flowering phenology, airborne pollen load and drought. Acta Oecol. 43, 51-59.

Fernández-Rodríguez, S., Skjøth, C.A., Tormo-Molina, R., Brandao, R., Caeiro, E., SilvaPalacios, I., et al., 2014a. Identification of potential sources of airborne Olea pollen in the Southwest Iberian Peninsula. Int. J. Biometeorol. 58, 337-348.

Fernández-Rodríguez, S., Tormo-Molina, R., Maya-Manzano, J.M., Silva-Palacios, I., GonzaloGarijo, Á., 2014b. Comparative study of the effect of distance on the daily and hourly pollen counts in a city in the south-western Iberian Peninsula. Aerobiologia 30, 173-187.

Fernández-Rodríguez, S., Adams-Groom, B., Silva-Palacios, I., Caeiro, E., Brandao, R., Ferro, R., et al., 2015. Comparison of Poaceae pollen counts recorded at sites in Portugal, Spain and the UK. Aerobiologia 31 (1), 1-10.

Fernández-Rodríguez, S., Durán-Barroso, P., Silva-Palacios, I., Tormo-Molina, R., MayaManzano, J.M., Gonzalo-Garijo, Á., 2016a. Quercus long-term pollen season trends in the southwest of the Iberian Peninsula. Process Saf. Environ. Prot. 101, 152-159.

Fernández-Rodríguez, S., Durán-Barroso, P., Silva-Palacios, I., Tormo-Molina, R., MayaManzano, J.M., Gonzalo-Garijo, Á., 2016b. Regional forecast model for the Olea pollen season in Extremadura (SW Spain). Int. J. Biometeorol. 60, 1509-1517.

Gage, S.H., Isard, S.A., Colunga, -G.M., 1999. Ecological scaling of aerobiological dispersal processes. Agric. For. Meteorol. 97, 249-261.

Galán, C., Cariñanos, P., Alcázar, P., Dominguez-Vilches, E., 2007. Spanish Aerobiology Network (REA) Management and Quality Manual. Servicio de Publicaciones Universidad de Córdoba 978-84-690-6353-8.

García de León, D., García-Mozo, H., Galán, C., Alcázar, P., Lima, M., González-Andújar, J.L., 2015. Disentangling the effects of feedback structure and climate on Poaceae annual airborne pollen fluctuations and the possible consequences of climate change. Sci. Total Environ. 530-531, 103-109.

García-Mozo, H., Gómez-Casero, M.T., Domínguez, E., Galán, C., 2007. Influence of pollen emission and weather-related factors on variations in holm-oak (Quercus ilex subsp. ballota) acorn production. Environ. Exp. Bot. 61, 35-40.

García-Mozo, H., Chuine, I., Aira, M.J., Belmonte, J., Bermejo, D., Díaz de la Guardia, C., et al., 2008. Regional phenological models for forecasting the start and peak of the Quercus pollen season in Spain. Agric. For. Meteorol. 148, 372-380.

García-Mozo, H., Dominguez-Vilches, E., Galán, C., 2012. A model to account for variations in holm-oak (Quercus ilex subsp. ballota) acorn production in southern Spain. Ann. Agric. Environ. Med. 19, 403-408. 
García-Mozo, H., Oteros, J.A., Galán, C., 2016. Impact of land cover changes and climate on the main airborne pollen types in southern Spain. Sci. Total Environ. 548-549, 221-228.

Goode, J.P., 1925. The homolosine projection: a new device for portraying the earth's surface entire. Ann. Assoc. Am. Geogr. 15, 119-125.

Granger, C.W.J., 1969. Investigating causal relations by econometric models and crossspectral methods. Econométrica 37, 424-438.

Grundström, M., Adams-Groom, B., Pashley, C.H., Dahl, A., Rasmussen, K., de Weger, L.A., et al., 2019. Oak pollen seasonality and severity across Europe and modelling the season start using a generalized phenological model. Sci. Total Environ. $663,527-536$

Han, Y.G., Jung, S.H., Kwon, O., 2017. How to utilize vegetation survey using drone image and image analysis software. J. Ecol. Environ. 41.

Häusler, M., Silva, J.M.N., Cerasoli, S., López-Saldaña, G., Pereira, J.M.C., 2016. Modelling spectral reflectance of open cork oak woodland: a simulation analysis of the effects of vegetation structure and background. Int. J. Remote Sens. 37, 492-515.

He, Y., Lee, E., 2016. Empirical relationships of sea surface temperature and vegetation activity with summer rainfall variability over the Sahel. Earth Interact. 20.

He, B., Chen, A., Jiang, W., Chen, Z., 2017. The response of vegetation growth to shifts in trend of temperature in China. J. Geogr. Sci. 27, 801-816.

Hernández-Ceballos, M.A., García-Mozo, H., Adame, J.A., Domínguez-Vilches, E., Bolívar, J.P., De La Morena, B.A., et al., 2011. Determination of potential sources of Quercus airborne pollen in Córdoba city (southern Spain) using back-trajectory analysis. Aerobiologia 27, 261-276.

Hernández-Ceballos, M.A., García-Mozo, H., Galán, C., 2015. Cluster analysis of intradiurnal holm oak pollen cycles at peri-urban and rural sampling sites in southwestern Spain. Int. J. Biometeorol. 59, 517-531.

Hilgert-Moreira, S.B., Fernandes, M.Z., Marchett, C.A., Blochtein, B., 2014. Do different landscapes influence the response of native and non-native bee species in the Eucalyptus pollen foraging, in southern Brazil? For. Ecol. Manag. 313, 153-160.

Hirst, J.M., 1952. An automatic volumetric spore trap. Ann. Appl. Biol. 39, 257-265.

Hogda, K.A., Karlsen, S.R., Solheim, I., Tommervik, H., Ramfjord, H., 2002. The start dates of birch pollen seasons in Fennoscandia studied by NOAA AVHRR NDVI data. International Geoscience and Remote Sensing Symposium (IGARSS) 6, 3299-3301.

Huang, Y., Lan, Y., Ge, Y., Hoffmann, W.C., Thomson, S.J., 2010. Spatial modeling and variability analysis for modeling and prediction of soil and crop canopy coverage using multispectral imagery from an airborne remote sensing system. Trans. ASABE 53, 1321-1329.

Ibáñez, J.J., Gómez, R.P., 2016. In: Zinck, J.A., Metternicht, G., Bocco, G., Del Valle, H.F. (Eds.), Geopedology: An Integration of Geomorphology and Pedology for Soil and Landscape Studies. Springer International Publishing, Cham, pp. 183-191 Diversity of soil-landscape relationships: state of the art and future challenges. In.

Ibáñez, J.J., Pérez-Gómez, R., Brevik, E.C., Cerdà, A., 2016. Islands of biogeodiversity in arid lands on a polygons map study: detecting scale invariance patterns from natural resources maps. Sci. Total Environ. 573, 1638-1647.

Iglesias-Otero, M.A., Fernández-González, M., Rodríguez-Caride, D., Astray, G., Mejuto, J.C., Rodríguez-Rajo, F.J., 2015. A model to forecast the risk periods of Plantago pollen allergy by using the ANN methodology. Aerobiologia 31, 201-211.

IPCC, 2017. IPCC-46 and Working Group I, II, III Sessions Montreal, Canada, 6-10 September 2017.

Jato, V., Rodríguez-Rajo, F.J., Méndez, J., Aira, M.J., 2002. Phenological behaviour of Quercus in Ourense (NW Spain) and its relationship with the atmospheric pollen season. Int. J. Biometeorol. 46, 176-184.

Jiang, B., Liang, S., Yuan, W., 2015. Observational evidence for impacts of vegetation change on local surface climate over northern China using the Granger causality test. J. Geophys. Res. 120, 1-12 Biogeosciences.

Jing, H., Huimin, W., Qiang, D., Dawei, H., 2014. Analysis of ndvi data for crop identification and yield estimation. IEEE J. Sel. Top. Appl. Earth Obs. Remote Sens. 2014 (7), 4374-4384.

Karlsen, S.R., Elvebakk, A., Høgda, K.A., Johansen, B., 2006. Satellite-based mapping of the growing season and bioclimatic zones in Fennoscandia. Glob. Ecol. Biogeogr. 15, 416-430.

Karlsen, S.R., Tolvanen, A., Kubin, E., Poikolainen, J., Høgda, K.A., Johansen, B., 2008. MODIS-NDVI based mapping of the length of the growing season in northern Fennoscandia. Int. J. Appl. Earth Obs. Geoinf. 10, 253-266.

Karlsen, S.R., Ramfjord, H., Høgda, K.A., Johansen, B., Danks, F.S., Brobakk, T.E., 2009. A satellite-based map of onset of birch (Betula) flowering in Norway. Aerobiologia $25,15-25$.

Lakshmi Kumar, T.V., Rao, K.K., Barbosa, H., Jothi, E.P., 2013. Studies on spatial pattern of NDVI over India and its relationship with rainfall, air temperature, soil moisture adequacy and ENSO. Geofizika 30, 1-18.

Lapedes, A., Farber, R., 1988. How neural nets work. In: Anderson, D.Z. (Ed.), Neural Information Processing Systems. AIP Press, New York.

Leggett, L.M.W., Ball, D.A., 2014. First and second derivative atmospheric CO2, global surface temperature and ENSO. Atmos. Chem. Phys. 14, 29101-29157.

Leggett, L.M.W., Ball, D.A., 2015. Granger causality from changes in level of atmospheric $\mathrm{CO} 2$ to global surface temperature and the El Niño-Southern Oscillation, and a candidate mechanism in global photosynthesis. Atmos. Chem. Phys. 15, 11571-11592.

Lehmann, J.R.K., Nieberding, F., Prinz, T., Knoth, C., 2015. Analysis of unmanned aerial system-based CIR images in forestry-a new perspective to monitor pest infestation levels. Forests 6, 594-612.

Li, Y., Cao, Z., Long, H., Liu, Y., Li, W., 2017. Dynamic analysis of ecological environment combined with land cover and NDVI changes and implications for sustainable urban-rural development: the case of Mu Us Sandy Land, China. J. Clean. Prod. 142, 697-715.
Lillesand, T.M., Kiefer, R., 1994. Remote Sensing and Image Interpretation. 3rd ed. Wiley, New York.

Liu, Y., Hill, M.J., Zhang, X., Wang, Z., Richardson, A.D., Hufkens, K., et al., 2017. Using data from Landsat, MODIS, VIIRS and PhenoCams to monitor the phenology of California oak/grass savanna and open grassland across spatial scales. Agric. For. Meteorol. 237-238, 311-325.

Lu, S., Inoue, S., Shibaike, H., Kawashima, S., Yonemura, S., Du, M., 2015. Special collection: sensing and monitoring research group, samj: detection potential of maize pollen release stage by using vegetation indices and red edge obtained from canopy reflectance in visible and NIR region. J. Agric. Meteorol. 71, 153-160.

Ma, X., Huete, A., Yu, Q., Coupe, N.R., Davies, K., Broich, M., et al., 2013. Spatial patterns and temporal dynamics in savanna vegetation phenology across the North Australian Tropical Transect. Remote Sens. Environ. 139, 97-115.

Makra, L., Matyasovszky, I., Tusnády, G., Wang, Y., Csépe, Z., Bozóki, Z., et al., 2016. Biogeographical estimates of allergenic pollen transport over regional scales: common ragweed and Szeged, Hungary as a test case. Agric. For. Meteorol. 221, 94-110.

Maya-Manzano, J.M., Fernández-Rodríguez, S., Smith, M., Tormo-Molina, R., Reynolds, A. Silva-Palacios, I., et al., 2016. Airborne Quercus pollen in SW Spain: identifying favourable conditions for atmospheric transport and potential source areas. Sci. Total Environ. 571, 1037-1047.

Maya Manzano, J.M., Sadyś, M., Tormo Molina, R., Fernández Rodríguez, S., Oteros, J., Silva Palacios, I., et al., 2017. Relationships between airborne pollen grains, wind direction and land cover using GIS and circular statistics. Sci. Total Environ. 584-585, 603-613.

Maya-Manzano, J.M., FernÁndez-Rodríguez, S., Silva-Palacios, I., Gonzalo-Garijo, Á., Tormo-Molina, R., 2018. Comparison between two adhesives (silicone and petroleum jelly) in Hirst pollen traps in a controlled environment. Grana 57, 137-143.

Morillo, J., Espejo, A.M., 2008. Determinación de la superficie ocupada por las áres adhesada en Extremadurua. La agricultura y la ganadería extremeñas en 2007 Junta de Extremadura.

Olchev, A., Novenko, E., Popov, V., Pampura, T., Meili, M., 2017. Evidence of temperature and precipitation change over the past 100 years in a high-resolution pollen record from the boreal forest of Central European Russia. Holocene 27, 740-751.

Oteros, J., García-Mozo, H., Hervás, C., Galán, C., 2013. Biometeorological and autoregressive indices for predicting olive pollen intensity. Int. J. Biometeorol. 57, 307-316.

Ottosen, T.B., Lommen, S.T.E., Skjøth, C.A., 2019. Remote sensing of cropping practice in Northern Italy using time-series from Sentinel-2. Comput. Electron. Agric. 157, 232-238.

Parmesan, C., Yohe, G., 2003. A globally coherent fingerprint of climate change impacts across natural systems. Nature 421, 37-42.

Philippon, N., Mougin, E., Jarlan, L., Frison, P.L., 2005. Analysis of the linkages between rainfall and land surface conditions in the West African monsoon through CMAP ERS-WSC, and NOAA-AVHRR data. J. Geophys. Res. Atmos. 110, 1-14.

Pinto, C.A., Henriques, M.O., Figueiredo, J.P., David, J.S., Abreu, F.G., Pereira, J.S., et al., 2011. Phenology and growth dynamics in Mediterranean evergreen oaks: effects of environmental conditions and water relations. For. Ecol. Manag. 262, 500-508.

Puc, M., 2012. Artificial neural network model of the relationship between Betula pollen and meteorological factors in Szczecin (Poland). Int. J. Biometeorol. 56, 395-401.

RC Team, 2014. R: A Language and Environment for Statistical Computing. R Foundation for Statistical Computing, Vienna, Austria URL. http://www.R-project.org/.

Ríos, B., Torres-Jardón, R., Ramírez-Arriaga, E., Martínez-Bernal, A., Rosas, I., 2016. Diurnal variations of airborne pollen concentration and the effect of ambient temperature in three sites of Mexico City. Int. J. Biometeorol. 60, 771-787.

Rojo, J., Pérez-Badia, R., 2015. Spatiotemporal analysis of olive flowering using geostatistical techniques. Sci. Total Environ. 505, 860-869.

Romero-Morte, J., Rojo, J., Rivero, R., Fernández-González, F., Pérez-Badia, R., 2018 Standardised index for measuring atmospheric grass-pollen emission. Sci. Total Environ. 612, 180-191.

Sánchez-Mesa, J.A., Galan, C., Martínez-Heras, J.A., Hervás-Martínez, C., 2002. The use of a neural network to forecast daily grass pollen concentration in a Mediterranean region: the southern part of the Iberian Peninsula. Clin Exp Allergy 32, 1606-1612.

Scheifinger, H., Belmonte, J., Buters, J., Celenk, S., Damialis, A., Dechamp, C., et al., 2012. Monitoring, modelling and forecasting of the pollen season. In: Sofiev, M. Bergmann, K.C. (Eds.), Allergenic Pollen: A Review of the Production, Release, Distribution and Health Impacts. Springer, Dordrecht.

Seinfeld, J.H., Pandis, S.N., 2006. Atmospheric Chemistry and Physics: From Air Pollution to Climate Change. John Wiley and Sons, New York.

Silva-Palacios, I., Fernández-Rodríguez, S., Durán-Barroso, P., Tormo-Molina, R., MayaManzano, J.M., Gonzalo-Garijo, Á., 2016. Temporal modelling and forecasting of the airborne pollen of Cupressaceae on the southwestern Iberian Peninsula. Int J. Biometeorol. 60, 297-306.

Skjøth, C.A., Ørby, P.V., Becker, T., Geels, C., Schlünssen, V., Sigsgaard, T., et al., 2013. Identifying urban sources as cause of elevated grass pollen concentrations using GIS and remote sensing. Biogeosciences 10, 541-554.

Skjøth, C.A., Baker, P., Sadyś, M., Adams-Groom, B., 2015. Pollen from alder (Alnus sp.), birch (Betula sp.) and oak (Quercus sp.) in the UK originate from small woodlands. Urban Clim. 14, 414-428.

Szilassi, P., Bata, T., Szabó, S., Czúcz, B., Molnár, Z., Mezősi, G., 2017. The link between landscape pattern and vegetation naturalness on a regional scale. Ecol. Indic. 81, 252-259.

Taghipour Javi, S., Malekmohammadi, B., Mokhtari, H., 2014. Application of geographically weighted regression model to analysis of spatiotemporal varying relationships between groundwater quantity and land use changes (case study: Khanmirza Plain, Iran). Environ. Monit. Assess. 186, 3123-3138.

Tormo-Molina, R., Maya-Manzano, J.M., Fernández-Rodríguez, S., Gonzalo-Garijo, Á. Silva-Palacios, I., 2013. Influence of environmental factors on measurements with Hirst spore traps. Grana 52, 59-70. 
Tormo-Molina, R., Maya-Manzano, J.M., Silva-Palacios, I., Fernández-Rodríguez, S. Gonzalo-Garijo, Á., 2015. Flower production and phenology in Dactylis glomerata. Aerobiologia 31, 469-479.

Uguz, U., Guvensen, A., Tort, N.S., 2017. Annual and intradiurnal variation of dominant airborne pollen and the effects of meteorological factors in Çeșme (Izmir, Turkey). Environ. Monit. Assess. 189.

Velasco-Jiménez, M.J., Alcázar, P., Domínguez-Vilches, E., Galán, C., 2013. Comparative study of airborne pollen counts located in different areas of the city of Córdob (south-western Spain). Aerobiologia 29, 113-120.

Velasco-Jiménez, M.J., Arenas, M., Alcázar, P., Galán, C., Domínguez-Vilches, E., 2015. Aerobiological and phenological study of Pistacia in Córdoba city (Spain). Sci. Total Environ. 505, 1036-1042.

Voukantsis, D., Niska, H., Karatzas, K., Riga, M., Damialis, A., Vokou, D., 2010. Forecasting daily pollen concentrations using data-driven modeling methods in Thessaloniki, Greece. Atmos. Environ. 44, 5101-5111.

Walker, J.J., de Beurs, K.M., Henebry, G.M., 2015. Land surface phenology along urban to rural gradients in the U.S. Great Plains. Remote Sens. Environ. 165, 42-52.
Wang, J., Zhang, Z., Greimann, B., Huang, V., 2018. Application and evaluation of the HECRAS - riparian vegetation simulation module to the Sacramento River. Ecol. Model. 368, 158-168.

White, M.A., Nemani, R.R., 2006. Real-time monitoring and short-term forecasting of land surface phenology. Remote Sens. Environ. 104, 43-49.

Yu, H., Jiang, S., Land, K.C., 2015. Multicollinearity in hierarchical linear models. Soc. Sci. Res. 53, 118-136.

Zhang, X., 2015. Reconstruction of a complete global time series of daily vegetation index trajectory from long-term AVHRR data. Remote Sens. Environ. 156, 457-472.

Zhang Guoqiang, B., Patuwo, E., Y, H.M., 1998. Forecasting with artificial neural network: the state of the art. Int. J. Forecast. 14, 35-62.

Zhu, L., Meng, J., 2014. Determining the relative importance of climatic drivers on spring phenology in grassland ecosystems of semi-arid areas. Int. J. Biometeorol. 59, 237-248. 